\title{
Influence of poly( $N$-isopropylacrylamide)-CNT- polyaniline three-dimensional electrospun microfabric scaffolds on cell growth and viability
}

\author{
Ashutosh Tiwari, Yashpal Sharma, Hattori Shinya, Terada Dohiko, Sharma Ashok K., \\ Anthony P. F. Turner and Hisatoshi Kobayashi
}

\section{Linköping University Post Print}

N.B.: When citing this work, cite the original article.

This is the authors' version of the following article:

Ashutosh Tiwari, Yashpal Sharma, Hattori Shinya, Terada Dohiko, Sharma Ashok K., Anthony P. F. Turner and Hisatoshi Kobayashi, Influence of poly( $N$-isopropylacrylamide)CNT-polyaniline three-dimensional electrospun microfabric scaffolds on cell growth and viability, 2012, Biopolymers.

which has been published in final form at:

http://dx.doi.org/10.1002/bip.22170

Copyright: Wiley-Blackwell

http://eu.wiley.com/WileyCDA/Brand/id-35.html

Postprint available at: Linköping University Electronic Press http://urn.kb.se/resolve?urn=urn:nbn:se:liu:diva-85583 


\section{Influence of poly( $N$-isopropylacrylamide)-CNT-polyaniline three- dimensional electrospun microfabric scaffolds on cell growth and viability}

Ashutosh Tiwari ${ }^{1,2,3^{*}}$, Yashpal Sharma ${ }^{2,4}$, Shinya Hattori ${ }^{2}$, Dohiko Terada ${ }^{2}$, Ashok K. Sharma ${ }^{5}$, Anthony P. F. Turner ${ }^{1}$ and Hisatoshi Kobayashi ${ }^{2,6^{*}}$

${ }^{1}$ Biosensors and Bioelectronics Centre, Institute of Physics, Chemistry and Biology, Linköping University, S-58183, Linköping, Sweden

${ }^{2}$ International Center for Materials Nanoarchitectonics, National Institute for Materials Science, 1-2-1, Sengen, Tsukuba, Ibaraki 305-0047, Japan

${ }^{3}$ Linköping Integrative Regenerative Medicine (IGEN) Centre, IKE-Linköping University, S-581 83 Linköping, Sweden

${ }^{4}$ Department of Chemistry, G. J. University of Science and Technology, Hisar 125-001, India

${ }^{5}$ Department of Materials Science and Nanotechnology, D. C. R. University of Science and Technology, Murthal 131-039, India

${ }^{6}$ JST-CREST, 5 Sanbancho, Chiyoda-ku, Tokyo 102-0075, Japan

*Corresponding authors.

E-mail: A. Tiwari (ashutosh.tiwari@liu.se); H. Kobayashi (kobayashi.hisatosh@nims.go.jp);

Tel: (+81) 29-860-4495; and Fax: (+81) 29-859-2247. 


\section{ABSTRACT}

This study investigates the effect on: 1) the bulk surface; and 2) the three-dimensional nonwoven microfabric scaffolds of poly( $N$-isopropylacylamide)-CNT-polyaniline on growth and viability of mice fibroblast cells L929. The poly( $N$-isopropylacylamide)-CNT-polyaniline was prepared using coupling chemistry and electrospinning was then used for the fabrication of responsive, nonwoven microfabric scaffolds. The electrospun microfabrics were assembled in regular three-dimensional scaffolds with OD: 400-500 $\mu \mathrm{m}$; L: 6-20 cm. Mice fibroblast cells L929 were seeded on the both poly( $N$-isopropylacylamide)-CNT-polyaniline bulk surface as well as non-woven microfabric scaffolds. Excellent cell proliferation and viability was observed on poly( $N$-isopropylacylamide)-CNT-polyaniline non-woven microfabric matrices in compare to poly( $N$-isopropylacylamide)-CNT-polyaniline bulk and commercially available Matrigel ${ }^{\mathrm{TM}}$ even with a range of cell lines up to $168 \mathrm{~h}$. Temperature dependent cells detachment behaviour was observed on the poly( $N$-isopropylacylamide)CNT-polyaniline scaffolds by varying incubation at below lower critical solution temperature (LCST) of poly( $N$-isopropylacylamide). The results suggest that poly( $N$-isopropylacylamide)CNT-polyaniline non-woven microfabrics could be used as a smart matrices for applications in tissue engineering.

KEYWORDS: smart tissue engineering scaffolds, conducting polymers, carbon nanotubes, responsive-polymers, biocompatible conducting matrices. 


\section{INTRODUCTION}

Conducting polymers are proven and widely applied materials with electronic and ionic conductivity. ${ }^{1,2}$ A range of new biomedical applications are currently being considered using conducting polymers including development of artificial muscles, ${ }^{3}$ controlled drug release, ${ }^{4,5}$ neural recording ${ }^{6}$ and stimulation of nerve regeneration. ${ }^{7}$ Moreover, electrically active tissues such as brain, heart and skeletal muscle offer opportunities to couple them with electronic devices and computers to create therapeutic body-machine interfaces. ${ }^{8}$ These possibilities make them an important class of materials for bioelectronics. Of various conducting polymer, polyaniline is a well-known, versatile conducting material, which has found particular biological utility due to its ease of availability and/or synthesis via chemical and/or electrochemical methods, environmental stability, inexpensive and classical electrical and electronic properties. Bidez et al. reported the biocompatibility and cell adhesion behaviour of polyaniline in both conducting, i.e., emeraldeine salt, and non-conducting, i.e., emeraldeine base forms. ${ }^{9}$ This work facilitates the possibility of smart conductive scaffolds to be used in a range of biomedical applications.

Carbon nanotubes (CNTs) have also attracted much interest in diverse applications due to their unique structural, mechanical and electronic properties. ${ }^{10} \mathrm{CNTs}$ are popularly applied in energy storage devices, where they are used as a filler to provide mechanical strength in polymeric nanocomposites, although new investigation of CNTs and CNTs based composites have also found application in the biomedical field. ${ }^{11-13}$ Recent studies indicated that materials, with or without pre-treatment to promote cell proliferation, exhibited desirable synergistic effects with cells. Such scaffolds can exhibit a well-defined, biocompatible threedimensional microstructure, which could provide better access for cells to growth factors for regular cellular activities. Furthermore, temperature change is a widely observed phenomenon in physiological systems. Temperature-sensitive materials have, therefore, 
attracted significant attention due to their ability to respond intelligently to temperature changes. It is worth noting that a novel design of temperature-responsive materials, which are capable of responding to external temperature, have been reported in the literature. ${ }^{14-16}$ The systems are derived from poly( $N$-isopropylacylamide) and exhibit a lower critical solution temperature (LCST) ranging from 32 to $34{ }^{\circ} \mathrm{C}$. These poly( $N$-isopropylacylamide)-based materials normally show efficient bioactivity at an ambient temperature, when the transition status of hydrophilicity is present. After their phase transitions to hydrophobicity upon changes of external temperature, the polymeric matrices become insoluble to water, thereby causing a dramatic decrease in the diffusion of substrates. Based on this mechanism, $\operatorname{poly}(N-$ isopropylacylamide)-based matrices could act as controllable temperature-responsive bioswitches for biomedical and biotechnology applications. ${ }^{17-20}$

Taking advantage of the excellent mechanical strength, cost-effectiveness, ease of preparation and high surface-to-volume ratio of these three-dimensional microfabric scaffolds, and utilising novel stimuli-responsive functional materials with temperature selfcontrol ability could be highly useful for the advancement of tissue engineering technology. In this report, we have fabricated electrospun microfabrics of a covalently attached $\operatorname{poly}(\mathrm{N}$ isopropylacylamide)-CNT-polyaniline. The advantages of microfabric scaffolds include excellent cells growth and viability with cells detachment behaviour by lowering incubation temperature from 37 to $20{ }^{\circ} \mathrm{C}$. Cell viability and proliferation were studied using mice fibroblast cells L929 and also cross checked with a range of other cell lines as preliminary tests for the potential application of $\operatorname{poly}(N$-isopropylacylamide)-CNT-polyaniline threedimensional non-woven microfabrics as temperature responsive scaffolds in the tissue regenerations. 


\section{EXPERIMENTAL SECTION}

Materials. Amine terminated, poly( $N$-isopropyl acrylamide $)\left(M_{\mathrm{n}}\right.$ 5,500; Aldrich, Schnelldorf, Germany); carboxyl functionalised multi-walled carbon nanotubes powder (HOOC-MWNTs, $>95 \%, 1-6 \%$ wt. -COOH functionalised, OD: 30-50 nm, L: 10-20 $\mu \mathrm{m}$, Nanostructured and Amorphous Materials Inc., Texas, USA), polyaniline $\left(M_{\mathrm{w}} 10,000\right.$; Aldrich, Schnelldorf, Germany), N,N'-dicyclohexylcarbodiimide (DCC, 99\%, Wako, Osaka, Japan), 1-ethyl-3-(3dimethylaminopropyl) carbodiimide hydrochloride (EDC, 99\%, Wako, Osaka, Japan) and $\mathrm{N}$ hydroxysuccinimide (NHS, 99\%, Wako, Osaka, Japan) were used as received from the companies. Foetal calf serum, penicillin, streptomycin and L-glutamine (complete media) were purchased from Sigma (Schnelldorf, Germany); and Matrigel $^{\mathrm{TM}}$, propidium iodide, Calcein-AM and 24-well plates were supplied by B. D. Biosciences (Tokyo, Japan), Dojin (Tokyo, Japan) and B. D. Falkon (Tokyo, Japan), respectively. All supplementary chemicals were used of analytical grade and solutions were prepared with Milli-Q water with resistance of $18.2 \mathrm{M} \Omega$.

$\begin{array}{lll}\text { Preparation } & \text { of } \quad \operatorname{poly}(N \text {-isopropylacylamide)-CNT-polyaniline. } & \operatorname{Poly}(N-\end{array}$ isopropylacylamide)-CNT-polyaniline was synthesised in two steps: 1) HOOC-MWNT was covalently coupled with polyaniline using $N, N^{\prime}$-dicyclohexylcarbodiimide (DCC) and $N$ hydroxysuccinimide (NHS) as coupling agents; ${ }^{21}$ and 2) poly( $N$-isopropylacylamide) was selectively grafted with residual carboxyl groups, i.e., -COOH groups available on the CNTpolyaniline through 1-ethyl-3-(3-dimethylaminopropyl) carbodiimide hydrochloride (EDC) and NHS mediate amide formation. ${ }^{22}$ 
Synthesis of CNT-polyaniline. The CNT-polyaniline was prepared by reacting $100 \mathrm{mg}$ of HOOC-MWNTs with $0.6 \mathrm{mM}$ polyaniline using $0.62 \mathrm{mM}$ of DCC and $0.65 \mathrm{mM}$ of NHS as coupling agents (Fig 1a). First, $100 \mathrm{mg}$ of HOOC-MWNTs was added into $25 \mathrm{~mL}$ of anhydrous dimethyl formamide under $>20 \mathrm{kHz}$ ultrasonic wave agitation for $2 \mathrm{~h}$. To this mixture, a calculated amount of polyaniline, DCC and NHS were added and then reaction was allowed to continue for $12 \mathrm{~h}$ under continuous stirring at room temperature. Unreacted reagents were then removed via dialysis using cellulose dialysis membrane ( $M_{\mathrm{w}}$ cut-off 10 $\mathrm{kDa}$ ) against anhydrous dimethyl formamide for $48 \mathrm{~h}$. CNT-polyaniline was filtered and dried under vacuum. CNT-polyaniline yield $(\%)=94.20$.

Synthesis of poly( $N$-isopropylacylamide)-CNT-polyaniline. The amine terminated, poly( $N$-isopropylacylamide) was covalently coupled with available carboxyl groups of the CNT-polyaniline using EDC and NHS as coupling agent (Fig. 1b). A $200 \mathrm{mg}$ aliquot of CNT-polyaniline was dispersed in $25 \mathrm{~mL}$ of dimethyl formamide under ultrasonication. To the resulting mixture, $75 \mathrm{~mL}$ aqueous solution containing $1.2 \mathrm{mM}$ amine terminated, poly $(\mathrm{N}$ isopropylacylamide), $1.25 \mathrm{mM}$ EDC and $1.3 \mathrm{mM}$ NHS were added under continuous stirring at room temperature and the reaction was allowed to proceed for $12 \mathrm{~h}$. The resulting $\operatorname{poly}(\mathrm{N}$ isopropylacylamide)-CNT-polyaniline was collected by dialysing the reaction solution using cellulose dialysis membrane $\left(M_{\mathrm{w}}\right.$ cut-off $\left.10 \mathrm{kDa}\right)$ against Milli-Q water for $48 \mathrm{~h}$. Next, poly( $N$-isopropylacylamide)-CNT-polyaniline was filtered and dried under vacuum. The Poly(N-isopropylacylamide)-CNT-polyaniline yieldwas $93.8 \%$.

Fabrication of three-dimensional electrospun microfabric scaffolds. The electrospun microfabric was obtained via a well-established needle-collector electrospinning method as shown in Fig. 1c. ${ }^{23}$ A typical electrospinning system with a rotating drum collector (NANON, 
MECC Co. Ltd., Japan) was employed to fabricate large nonwoven microfabric scaffolds. An $8 \mathrm{mg} / \mathrm{mL}$ solution of poly( $N$-isopropylacylamide)-CNT-polyaniline was prepared using 1,1,1,3,3,3-hexafluoro-2-propanol and $N, N$-dimethylformamide (8: 2, v/v) solvent mixture. Next, the solution mixture was placed for $12 \mathrm{~h}$ under moderate stirring at room temperature. The resulting homogeneous solution was taken up into a syringe $(1 \mathrm{~mL})$ fitted with a metallic needle of 22 gauze. The syringe was fixed horizontally on the syringe pump, and an electrode of high voltage power supply was clamped to the metal needle tip. The flow rate, voltage supply, humidity and distance of tip of needle to collector surface (i.e., aluminium foil) were $0.32 \mathrm{~mL} / \mathrm{h}, 15 \mathrm{kV},<15 \%$ and $24 \mathrm{~cm}$, respectively. Finally, the microfabric scaffolds (Fig. 1d) were collected on aluminium foil and dried in vacuum desiccators for $48 \mathrm{~h}$ at room temperature.

Characterisation. ${ }^{1} \mathrm{H}$ NMR spectroscopy was used to examine the chemical structure of synthesised samples. ${ }^{1} \mathrm{H}$ NMR spectra were obtained with a $600 \mathrm{MHz}$ Brucker DRX 600 spectrometer using tetramethylsilane as an internal standard at $20{ }^{\circ} \mathrm{C}$. The samples were prepared by dissolving $10 \mathrm{mg}$ of material in $1 \mathrm{~mL}$ of $\mathrm{CDCl}_{3}$ under stirring for $5 \mathrm{~h}$. The morphology of the bulk and electrospun microfabrics three-dimensional scaffolds based on poly( $N$-isopropylacylamide)-CNT-polyaniline was observed with a JEOL EDSEM scanning electron microscope (SEM) at accelerating voltage of $20 \mathrm{k}$. The aluminum foil containing electrospun microfabric was coated with about $5 \mathrm{~nm}$ thin layer of platinum using ELIONEX platinum coater prior to measurement.

Cell culture assay. Mice fibroblast cell line L929 was used to examine cell growth and viability on the poly( $N$-isopropylacylamide)-CNT-polyaniline electrospun microfabric threedimensional scaffolds and poly( $N$-isopropylacylamide)-CNT-polyaniline bulk 
nanocomposite. The cells were supplied by Riken cell bank, Tsukuba, Japan. In the cell culture, cells were directly placed over the surface of electrospun microfabrics in the medium supplemented with $10 \%(\mathrm{w} / \mathrm{v})$ foetal calf serum, penicillin/streptomycin and L-glutamine (complete medium) in 24 well tissue culture plate, c.f., the medium was changed every $72 \mathrm{~h}$. The tissue culture plate was incubated in a humidified environment at $37{ }^{\circ} \mathrm{C}$ with $5 \%(\mathrm{v} / \mathrm{v})$ $\mathrm{CO}_{2}$ supply. The cells $\left(1 \times 10^{4}\right.$ cells/well $)$ were seeded in respective cell culture plates and cells morphology and growth were assessed at 24, 48, 72, 96, 120, 144 and $168 \mathrm{~h}$. For cell viability, assays cell-loaded with electrospun microfabric scaffolds and bulk nanocomposite were washed with phosphate buffer solution (PBS) of $\mathrm{pH} 7.4$ and stained with $1 \mu \mathrm{L}$ of Calcein-AM and $1.5 \mu \mathrm{L}$ of propidium iodide (PI) for $30 \mathrm{~min}$ at $37{ }^{\circ} \mathrm{C}$. Cell viability was checked at $168 \mathrm{~h}$ after cells seeding. The cells detachment behaviour of scaffolds was accomplished by incubating culture plates at $20{ }^{\circ} \mathrm{C}$ for $2 \mathrm{~h}$. The control tests were also performed using the commercially available gel Matrigel $^{\mathrm{TM}}$ and native media under identical conditions.

All live cells were labelled with Calcein-AM, while dead cells were labelled with PI. Cells were imaged using an Olympus phase-contrast light microscope. To analyse cell growth, the number of cells present within a $0.15 \mathrm{~mm}^{2}$ area was determined with three representative images from each sample and each time point. All analyses were completed under identical conditions. When cell clumps were encountered they were counted as one unit, unless separate cells were resolvable. All the results are presented as 5th mean of standard deviation (SD).

\section{RESULTS AND DISCUSSION}

Synthesis, characterisation and scaffold fabrication of poly $(N$-isopropylacylamide)CNT-polyaniline. Poly( $N$-isopropylacylamide)-CNT-polyaniline was prepared via coupling 
chemistry as shown in Fig 1a-b: 1) HOOC-MWNTs and polyaniline using DCC/NHS; and followed by 2) grafting of amine terminated, $\operatorname{poly}(N$-isopropylacylamide $)$ on the CNTpolyaniline with EDC/NHS. The amine terminated, polyaniline and $\operatorname{poly}(N-$ isopropylacylamide) were grafted onto the HOOC-MWNTs one by one through amide bonds between the amine groups of polymers and the carboxylic acid groups of MWNTs. The threedimensional scaffords of poly( $N$-isopropylacylamide)-CNT-polyaniline were fabricated by the technique (Fig 1c-d). Typically, electrospun microfabrics were extruded under an anode spinneret with the electric force to grounded collector. Uniform non-woven microfabric without beads of poly( $N$-isopropylacylamide)-CNT-polyaniline was assembled in a threedimensional microstructure using $3 \mathrm{wt} \%$ of poly( $N$-isopropylacylamide $)$-CNT-polyaniline in 8: 2, v/v solvent system of 1,1,1,3,3,3-hexafluoro-2-propanol and $N, N$-dimethyl formamide at a fixed flow rate of $0.32 \mathrm{~mL} / \mathrm{h}$,. The voltage, humidity and distance from needle to collector were $15 \mathrm{kV},<15 \%$ and $24 \mathrm{~cm}$, respectively.

The chemical structure of poly( $N$-isopropylacylamide)-CNT-polyaniline was confirmed by ${ }^{1} \mathrm{H}$ NMR spectroscopy. The ${ }^{1} \mathrm{H}$ NMR spectrum of poly( $N$-isopropylacylamide)CNT-polyaniline is shown in Fig. 2A. The peaks at 1.1 ppm (a), 1.7 ppm (b), 2.1-2.2 ppm (c), 3.8-3.9 ppm (d) and 6.6-6.8 ppm (e) were due to presence of $-\mathrm{CH}_{3}$, isopropyl group, $>\mathrm{CH}-$ $\mathrm{C}=\mathrm{O}$, $-\mathrm{COOH},-\mathrm{CH}_{2}$ - long non-aromatic polymer chain and amide protons, respectively for HCOO-MWNTs coupled with poly( $N$-isopropylacylamide) chain by amide linkage. ${ }^{24}$ The aromatic protons were observed at about $6.9 \mathrm{ppm}$ whereas a triplet peak at about $7.5 \mathrm{ppm}$ was observed because of ammonium proton $\left(-\mathrm{N}^{+}-\mathrm{H}\right) .{ }^{25}{ }^{1} \mathrm{H}$ NMR spectrum was confirmed the formation of $\operatorname{poly}(N$-isopropylacylamide)-CNT-polyaniline.

A comparative morphology of bulk and electrospun microfabrics is shown in Fig. 2B. The typical SEM pictures of poly( $N$-isopropylacylamide)-CNT-polyaniline 1) bulk- shown miniature of fiber networks with polymeric plumps and 2) electrospun microfabrics- 
observed three-dimensional assembly of nonwoven microfabrics with OD: 400-500 $\mu \mathrm{m}, \mathrm{L}$ : 6-20 cm. The three-dimensional assembled scaffolds of poly( $N$-isopropylacylamide $)$-CNTpolyaniline electrospun microfabrics could be provided an uniform interconnectivity with high surface-to-volume ratio for the cells and nutrients. It directs to a higher degree of fibroblast cells growth and viability.

Cell culture assay. The feasibility of electrospun microfabrics of the $\operatorname{poly}(N-$ isopropylacylamide)-CNT-polyaniline for tissue engineering applications was assessed for potential cells matrices using mice L929 fibroblast cells as a model. Typically, fibroblast cells are very important and play a vital role in wound healing in the body. ${ }^{26}$ In the cell culture assay, the L929 fibroblast cells were seeded on the i) surface of bulk and ii) electrospun microfabrics of poly( $N$-isopropylacylamide)-CNT-polyaniline using Matrigel ${ }^{\mathrm{TM}}$ and native media as controls. The bulk poly( $N$-isopropylacylamide)-CNT-polyaniline was directly placed on 24 well tissue culture plate followed by cells seeding on the surface with complete media. Further, the tissue culture plate was incubated in a humidified environment at $37{ }^{\circ} \mathrm{C}$ with $5 \% \mathrm{CO}_{2}$ supply. In similar fashion, cells were also seeded on the threedimensional scaffolds of electrospun microfabrics, which were directly placed in 24-well tissue culture plate. The results show that poly( $N$-isopropylacylamide)-CNT-polyaniline (i.e., $0.1 \mathrm{wt} \%)$ was biocompatible and cells completely covered materials in the tissue culture plate. Cell growth on the bulk surface and electrospun microfabrics was calculated by counting the number of cells in a $0.15 \mathrm{~mm}^{2}$ area. The controls were media and the commercially available gel Matrigel ${ }^{\mathrm{TM}}$ containing cells. Fig. 3A shows a bar chart of cell growth in control, Matrigel ${ }^{\mathrm{TM}}$, bulk and electrospun microfabric scaffolds with $24 \mathrm{~h}$ cells seeding intervals. It can be seen that the electrospun microfabric scaffolds have more than twice the amount of cell growth as compared to controls and bulk at each time point, i.e., 
ranging from 24 to $168 \mathrm{~h}$. This suggests these scaffolds provide a highly compatible micro environment and/or surface for cell culture, attachment and proliferation, even comparison states have lower cells growth with or/and without poly( $N$-isopropylacylamide)-CNTpolyaniline, 0.1 wt.\%. The results support the conclusion that these three-dimensional scaffolds could be a useful material to support good cell growth for tissue engineering ${ }^{27,28}$. For any material to be used as a tissue engineering scaffold or in cell culture, a vital condition is a high order of biocompatibility, which means that materials should not poison cells or provide any obstacle to nutrient supply to the cells. The higher cell growth shown on both poly( $N$-isopropylacylamide)-CNT-polyaniline bulk and electrospun microfabric scaffolds can be attributed due to the balanced hydrophilic functions, conductance and mechanical strength provided by the poly( $N$-isopropylacrylamide), polyaniline and MWNTs, respectively. Fig. 3B show the morphology of the cells on $168 \mathrm{~h}$ of cells seeding on i) control; ii) Matrigel ${ }^{\mathrm{TM}}$; and $\operatorname{poly}(N$-isopropylacylamide)-CNT-polyaniline iii) bulk and iv) electrospun microfabric scaffolds. The cell morphologies also support the results indicated by the histogram in Fig. 3A. The cells were healthy, had regular growth and were even effectively dividing after $168 \mathrm{~h}$ of culture.

Cell viability was checked at $168 \mathrm{~h}$ ( 7 days) of culture. The cells were washed off the $\operatorname{poly}(N$-isopropylacylamide)-CNT-polyaniline bulk and electrospun microfabric scaffolds with PBS solution, pH 7.4. The cells were then stained by calcein-AM and PI dye followed by incubation at $37{ }^{\circ} \mathrm{C}$ with $5 \% \mathrm{CO}_{2}$ supply. Fig. $4 \mathrm{~A}$ indicates the cell viabilityin the: i) control, ii) Matrigel ${ }^{\mathrm{TM}}$ and surface of poly( $N$-isopropylacylamide)-CNT-polyaniline; iii) bulk and; iv) electrospun microfabrics, viz., green colour represents living cells whereas red colour corresponds to dead cells. On the basis of living and dead cells, the percentage living was calculated. Fig 4B shows the fluorescent micrographs of microblast cells seeded on: i) control; ii) MatrigelTM; iii) bulk and; iv) electrospun microfabrics scaffolds of $\operatorname{poly}(N$ - 
isopropylacylamide)-CNT-polyaniline, $0.1 \%$ wt. for $168 \mathrm{~h}$ intervals and stained with CalceinAM. The observation may be credited to factors such as biocompatibility of matrices, better accessibility of nutrients and gases, homogeneous micro environment, etc. A high degree of green fluorescence in all three cases indicates very good cell activities. Also cells were uniformly spread within the electrospun microfabric scaffold that favours again healthy cell proliferation within the three-dimensional micro environment. A major advantage of these scaffolds is that they do not require any pre-treatment such as pre-coating with adhesive proteins and/or growth factors for cell proliferation, which is usually needed with ionic scaffolds to facilitate homogeneous cells proliferation. ${ }^{29}$ The fundamental mechanism of improved cell proliferation is still unclear, however the well-defined three-dimensional microstructure, non-toxic non-woven poly( $N$-isopropylacylamide)-CNT-polyaniline electrospun microfabric scaffolds may provide fibroblast cells with better access to culture media. Although bulk poly( $N$-isopropylacylamide)-CNT-polyaniline, 0.1 wt.\% showed excellent biocompatibility, i.e., $95.38 \%$ cells living, electrospun microfabric scaffolds of $\operatorname{poly}(N$-isopropylacylamide)-CNT-polyaniline, $\quad 0.1 \quad$ wt. $\%$ had extremely high biocompatibility, i.e., approximately $100 \%$ cells living. In similar set of experiments using other cell types, i.e., A549, NHDF, NHLF, RLE6TN and HEK293, an excellent cell proliferation and viability was further examined on the non-woven microfabric $\operatorname{poly}(N-$ isopropylacylamide)-CNT-polyaniline matrices up to $168 \mathrm{~h}$ (Fig. 5). Thus, electrospun microfabric of poly( $N$-isopropylacylamide)-CNT-polyaniline could be potentially used as scaffolds in cell culture.

Moreover, we have also investigated the cell detachment behaviour of the scaffolds by lowering the incubation temperature of culture plates from 37 to $20^{\circ} \mathrm{C}$, i.e., below LCST of poly( $N$-isopropylacylamide). It was observed that at $20{ }^{\circ} \mathrm{C}$, poly $(N$-isopropylacylamide $)$ CNT-polyaniline scaffolds leached the cells, whereas controls resided the cells. It may be due 
to the poly( $N$-isopropylacylamide) chain in the nanocomposites which hydrates and hence cells detach from the surface. ${ }^{30}$

Further, the results evident the potential role of temperature-responsive $\operatorname{poly}(\mathrm{N}$ isopropylacrylamide) in the poly( $N$-isopropylacylamide)-CNT-polyaniline. At below and above the LCST, as the external temperature increases, i.e., above the LCST hydrogenbonding interactions become weakened or destroyed, consequently, the hydrophobic interactions among the hydrophobic moieties, i.e., $-\mathrm{CH}\left(\mathrm{CH}_{3}\right)_{2}$, -B-N-Q-, etc. become strong, which induces the freeing of the entrapped water molecules from the network, while the hydrophilic and ionic moieties, i.e., $-\mathrm{CONH}-,-\mathrm{NH}^{+}-$and $-\mathrm{COO}^{-}$may interact with media through hydrogen bonding at below LCST together with polyaniline network upon the HCOO-MWNTs. ${ }^{31}$ However, when the temperature reaches or is above the LCST, the hydrophobic interactions become dominant in the $\operatorname{poly}(N$-isopropylacylamide $)$-CNTpolyaniline and accordingly cells were happily survived at $37{ }^{\circ} \mathrm{C}$ in the scaffolds. Hence, combination of temperature responsive-conducting polymers together with CNTs could be used as an excellent smart matrix with outstanding cell viability and proliferation, as studied with a range of cell lines as a model test for the prospective applications of $\operatorname{poly}(\mathrm{N}$ isopropylacylamide)-CNT-polyaniline scaffolds in cell culture.

\section{CONCLUSION}

Poly( $N$-isopropylacylamide)-CNT-polyaniline was synthesised by coupling chemistry using polyaniline, HOOC-MWNT and amine terminated poly( $N$-isopropylacylamide) as principal components. A non-woven microfabric scaffold of poly( $N$-isopropylacylamide)-CNTpolyaniline was fabricated by electrospinning. The resulting electrospun microfabrics were endowed with a three-dimensional assembly of non-woven fabrics with OD: 400-500 $\mu \mathrm{m}$ and L: 6-20 cm. Proliferation and viability of a range of cell types were studied to explore the 
potential use of poly( $N$-isopropylacylamide)-CNT-polyaniline scaffolds for tissue engineering applications. The cell growth was compared on both the surface of bulk and on non-woven microfabric scaffolds of poly( $N$-isopropylacylamide)-CNT-polyaniline. It was observed that the microfabric scaffold provided an excellent surface for cell growth and proliferation as compared to bulk scaffolds and Matrigel ${ }^{\mathrm{TM}}$. These findings have led us with future prospective on the spatially ordered tissue architectures using heterotypic cell-cell interactions onto pattern depended temperature-responsive poly( $N$-isopropylacrylamide)CNT-polyaniline electrospun microfabric surfaces for heterotypic cells co-culture. The progress of these novel approaches will open up new edges for the regenerative medicine.

\section{ACKNOWLEDGEMENTS}

The authors thank Linköping University, Sweden and National Institute for Materials Science, Japan for providing facilities. We also wish to thank the European Commission (PIIF-GA-20 09-254955), JSPS, JST-CREST and MEXT for generous financial support to carry out this research. Y. Sharma owed his heartfelt special gratitude to the NIMS for internship FY2011 award.

\section{REFERENCES}

1. Xu, L. B.; Chen, W.; Mulchandani, A.; Yan, Y. Angew Chem Int Ed 2005, 44, 60096012

2. Tiwari, A.; Mishra, A. K.; Kobayashi, H.; Turner, A.P.F. Intelligent Nanomaterials, Wiley-Scrivener Publishing: Beverly, 2012; Chapter 21.

3. Otero, T. F.; Sansinena, J. M. Adv Mater 1998, 10, 491-494.

4. Abidian, M. R.; Kim, D. H.; Martin, D. C. Adv Mater 2006, 18, 405-409. 
5. Abidian, M. R.; Martin, D. C. Adv Funct Mater 2009, 19, 573-585.

6. Abidian, M. R.; Ludwig, K. A. ; Marzullo, T. C.; Martin, D. C.; Kipke, D. R. Adv Mater 2009, 21, 3764-3770.

7. Schmidt, C. E.; Shastri, V. R.; Vacanti, J. P.; Langer, R. Proc Natl Acad Sci USA 1997, 94, 8948-8953.

8. Yao, Z.-A.; Wu, H.-G. Adv. Mat. Lett. 2010, 1(1), 67-74.

9. Tiwari, A. J Polym Res 2008, 15, 337-342,

10. Tiwari, A.; Gong, S. Electroanalysis 2008, 20, 2119-2126.

11. Ramalingama, M.; Tiwari, A. Adv Mat Lett 2010, 1(3), 179-187.

12. Venkatesan, J.; Ryu, B. M.; Sudha, P. N.; Kim, S. K. Int J Biol Macromol 2012, 50, $393-402$.

13. Sharma, C.; Gautam, S.; Dinda, A. K.; Mishra, C.N. Adv Mat Lett 2011, 2(2), 90-99.

14. Schild, H. G. Prog Polym Sci 1992, 17, 163-249.

15. Bromberg, L. E.; Ron, E. S. Adv Drug Delivery Rev 1998, 31, 197-221.

16. Qiu Y.; Park K. Adv Drug Delivery Rev 2001, 53, 321-339.

17. Okano, T.; Bae, Y. H.; Jacobs, H.; Kim, S. W. J Controlled Release 1990, 11, 255-265.

18. Gutowska, A.; Bae, Y. H.; Feijen, J.; Kim, S. W. J Controlled Release 1992, 22, 95 104.

19. Stayton, P. S.; Shimobji, T.; Long, C.; Chilkoti, A.; Chen, G. H.; Harris, J. M.; Hoffman, A. S. Nature 1995, 378, 472-474.

20. Ganorkar, C. R.; Liu, F.; Baudy, M.; Kim, S. W. J Controlled Release 1999, 59, 287290.

21. Tiwari, A.; Aryal, S.; Pilla, S.; Gong, S. Talanta 2009, 78, 1401-1407.

22. Tiwari, A.; Terada, D.; Sharma, P. K.; Dutta, R. K.; Yoshikawa, C.; Pandey, A. C.; Kobayashi, H. Analytical Methods 2011, 3, 217-226. 
23. Tiwari, A.; Terada, D.; Yoshikawa, C.; Kobayashi, H. Talanta 2010, 82, 1725-1732.

24. Inglis, A. J.; Pierrat, P.; Muller, T.; Bräse, S.; Kowollik, C. B. Soft Matter 2010, 6, 8284.

25. Wang, X.; Sun, T.; Wang, C.; Wang, C.; Zhang, W.; Wei. Y. Macromol Chem Phys 2010, 211, 1814-1819.

26. Clark, R. A. F. Wound repair: overview and general considerations. In: The Molecular and Cellular Biology of Wound Repair. Clark, R. A. F., editor. London: Plenum Press, 1996; 3-50.

27. Kim, W.; Lee, K. G.; Kang, S.W.; Kweon, H.Y.; Park, Y.H. Biopolymers 2012, 97, $265-275$.

28. Prabhakaran, M.P.; Nair, A.S.; Kai, D.; Ramakrishna, S. Biopolymers 2012, 97, 529538.

29. Tiwari, A.; Grailer, J. J.; Pilla, S.; Steeber, D. A.; Gong, S. Acta Biomaterialia 2009, 5, $3441-3452$

30. Yang, J.; Yamato, M.; Nishida, K.; Ohki, T.; Kanzaki, M.; Sekine, H.; Shimizu, T.; Okano, T. J. Controlled Release 2006, 116, 193.

31. Shukla, S. K.; Bharadvaja, A.; Tiwari, A.; Parashar, G. K.; Dubey, G. C. Adv. Mat. Lett. 2010, 1(2), 129-134. 


\section{Figure Captions}

Fig. 1. a) Chemical synthesis of CNT-polyaniline; b) grafting of amine terminated, $\operatorname{poly}(\mathrm{N}$ isopropylacylamide) onto the CNT-polyaniline; c) setup for electrospinning and processing of microfabric scaffolds of poly( $N$-isopropylacylamide)-CNT-polyaniline; and d) schematic illustration of microfabric scaffold.

Fig. 2. A) ${ }^{1} \mathrm{H}$ NMR spectrum of poly( $N$-isopropylacylamide)-CNT-polyaniline and B) SEM images of poly( $N$-isopropylacylamide)-CNT-polyaniline: (i) bulk and (ii) electrospun nonwoven microfabrics with inset at higher resolution.

Fig. 3. (A) Cell proliferation assay, the bar chart indicates the viable cell number/ $0.15 \mathrm{~mm}^{2}$ of control, Matrigel $^{\mathrm{TM}}$, poly( $N$-isopropylacylamide)-CNT-polyaniline of bulk and electrospun microfabric scaffolds at various time points. Differences were significant; $* \mathrm{p}<0.05$ and ** $p<0.005$ vs. $1 \mathrm{~h}$, unless otherwise indicated. (B) Cell morphology of neo-fibroblast cells formed in the (i) control, (ii) Matrigel ${ }^{\mathrm{TM}}$, and poly( $N$-isopropylacylamide)-CNT-polyaniline, $0.1 \mathrm{wt} \%$ of (iii) bulk and (iv) three-dimensional electrospun non-woven microfabrics scaffolds after 168 h. Cells were stained with Calcein-AM.

Fig. 4. (A) Living/dead cell assay, the bar chart indicates the present of live cells in the control, Matrigel $^{\mathrm{TM}}$, bulk, and electrospun microfabric scaffolds. (B) Cells images after 168 $\mathrm{h}$ of cell culture for showing the viability in the: (i) control; (ii) Matrigel $^{\mathrm{TM}}$; (iii) bulk; and (iv) electrospun microfabric scaffolds after $168 \mathrm{~h}$. Cells were stained with Calcein-AM and PI. 
Fig. 5. (A) Cell proliferation assay, the bar chart indicates the viable A549, NHDF, NHLF, RLE6TN and HEK293 cell number/0.15 $\mathrm{mm}^{2}$ of poly( $N$-isopropylacylamide)-CNTpolyaniline of electrospun microfabric scaffolds at various time points. (B) Living/dead cell assay, the bar chart indicates the present of live A549, NHDF, NHLF, RLE6TN and HEK293 cells in the electrospun microfabric scaffolds. 


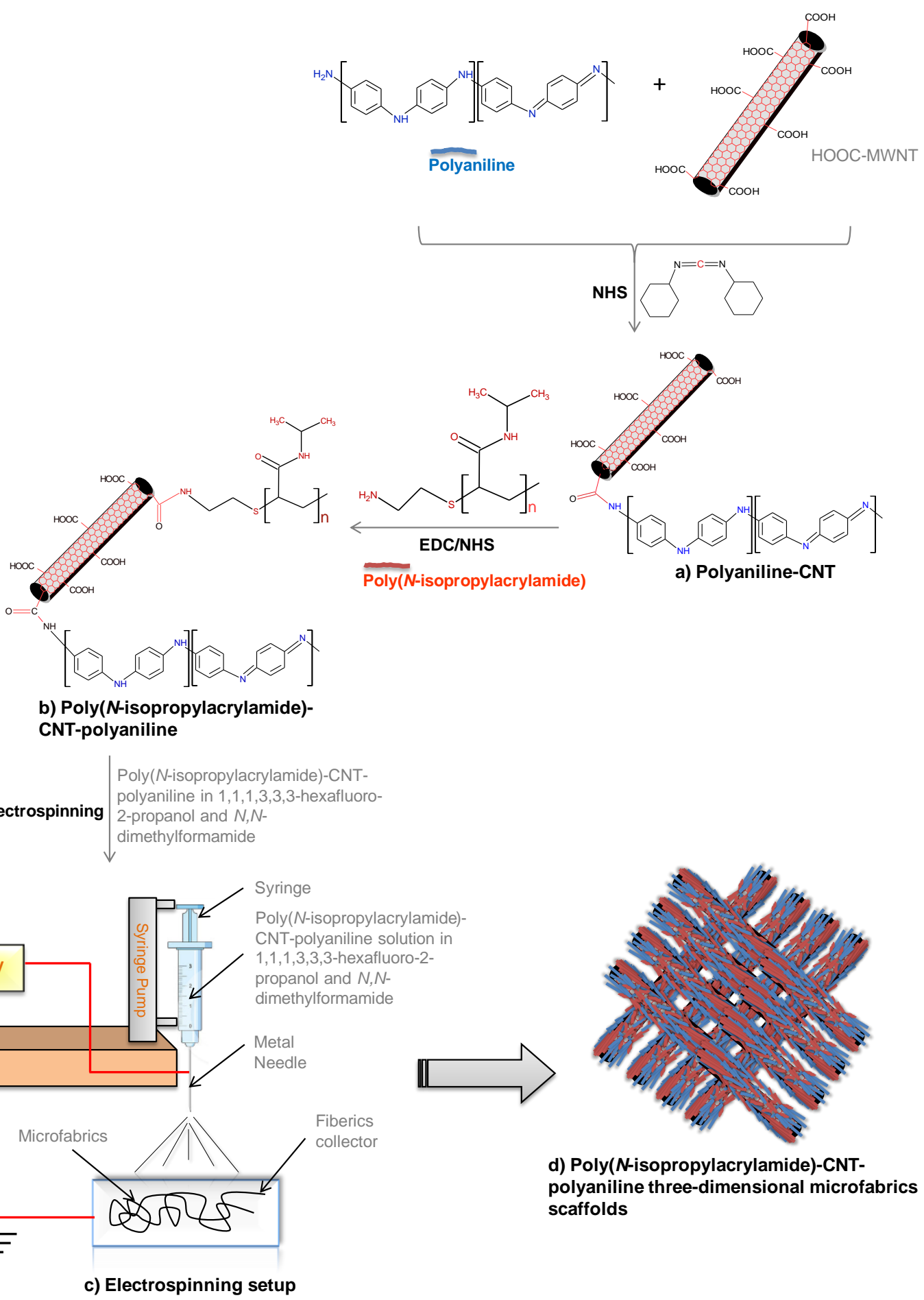

Fig. 1. 

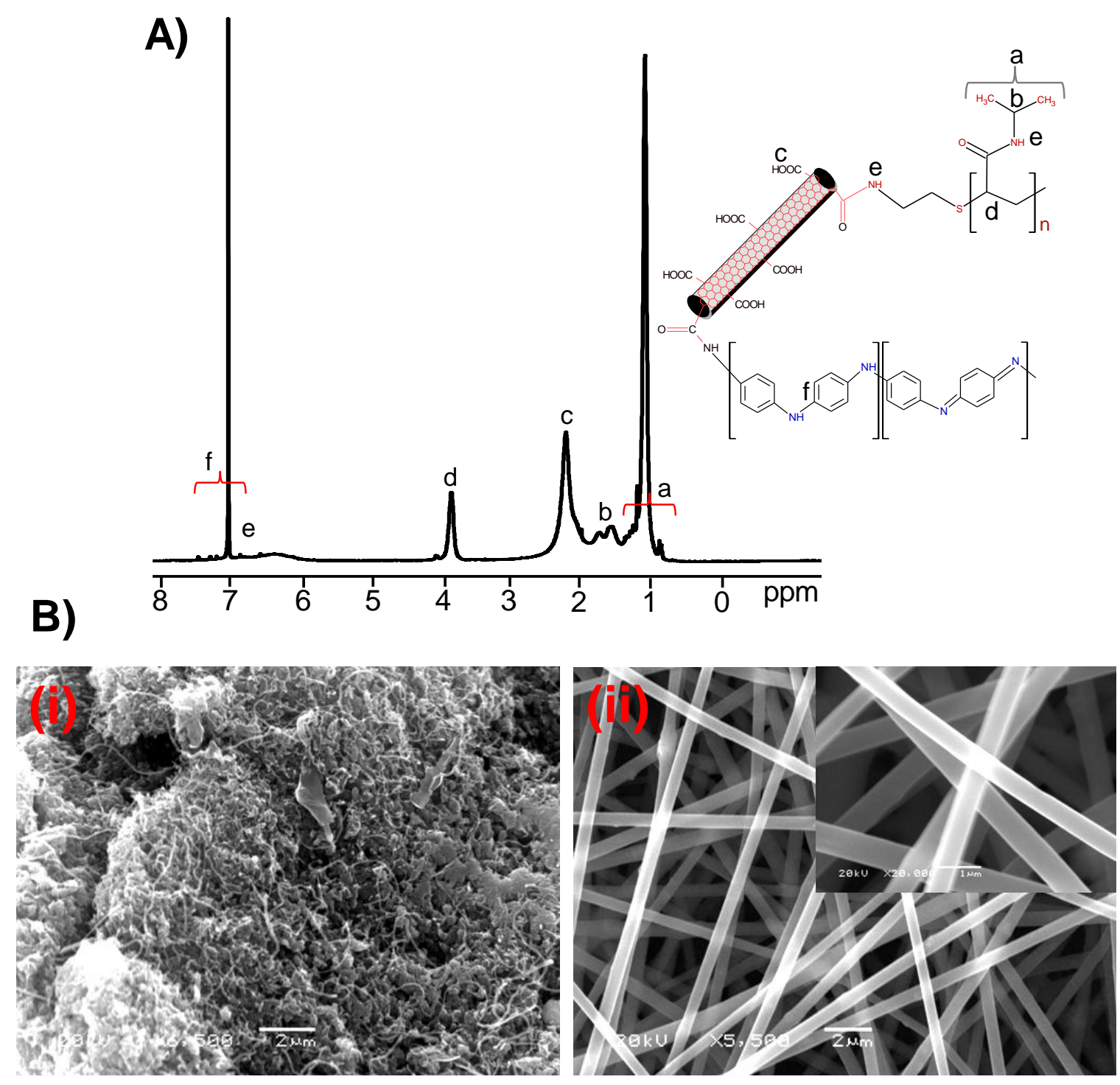

Fig. 2. 


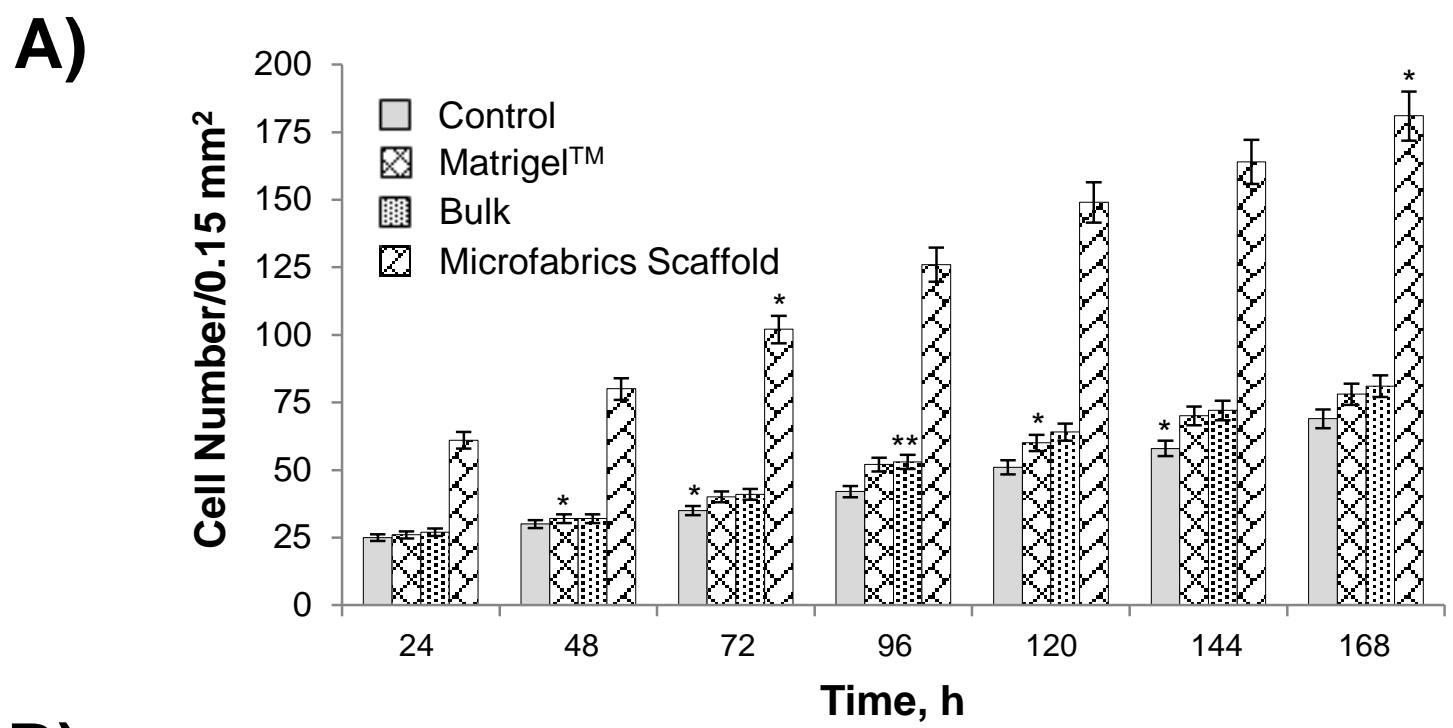

B)
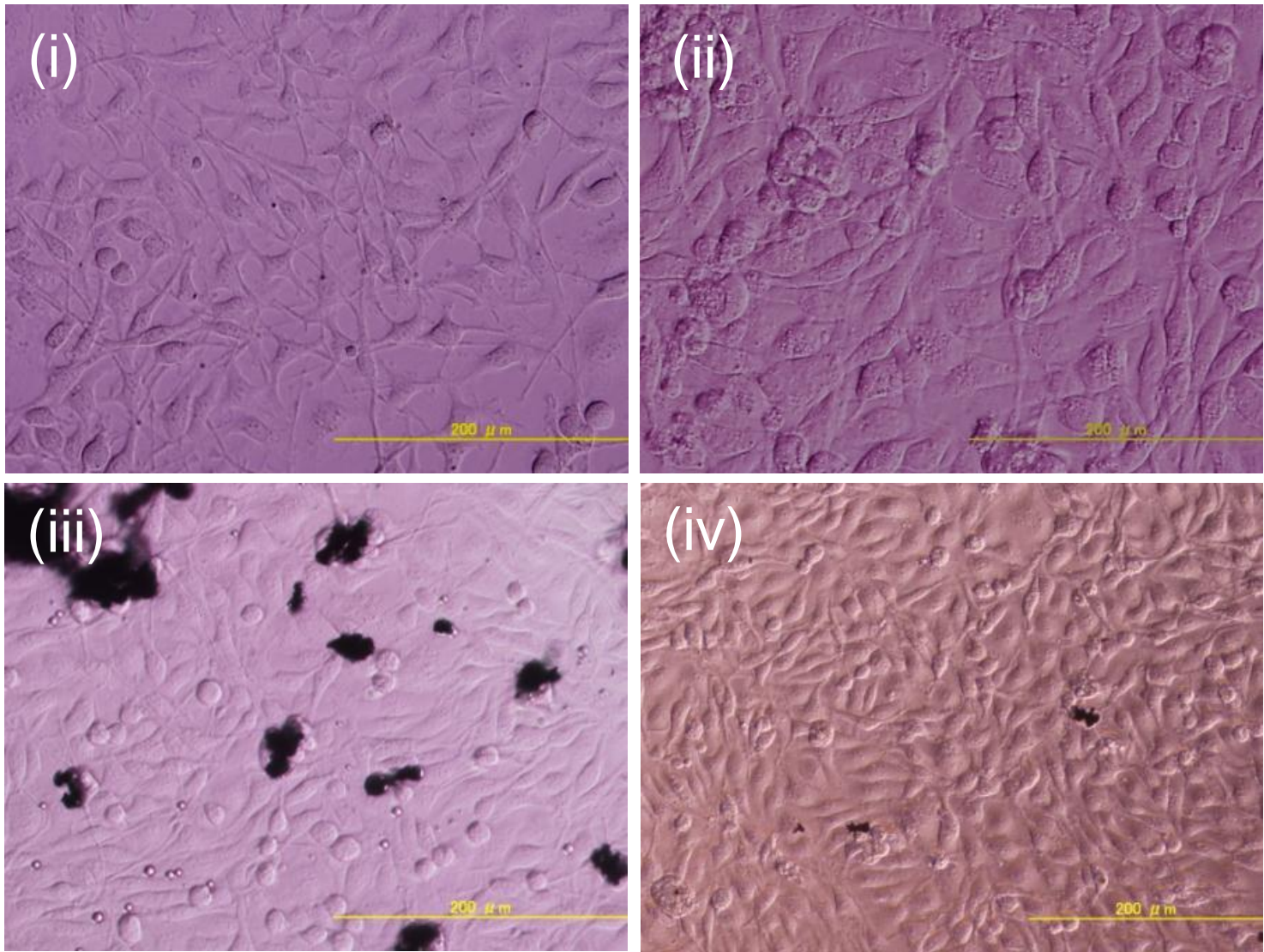

Fig. 3. 
A)

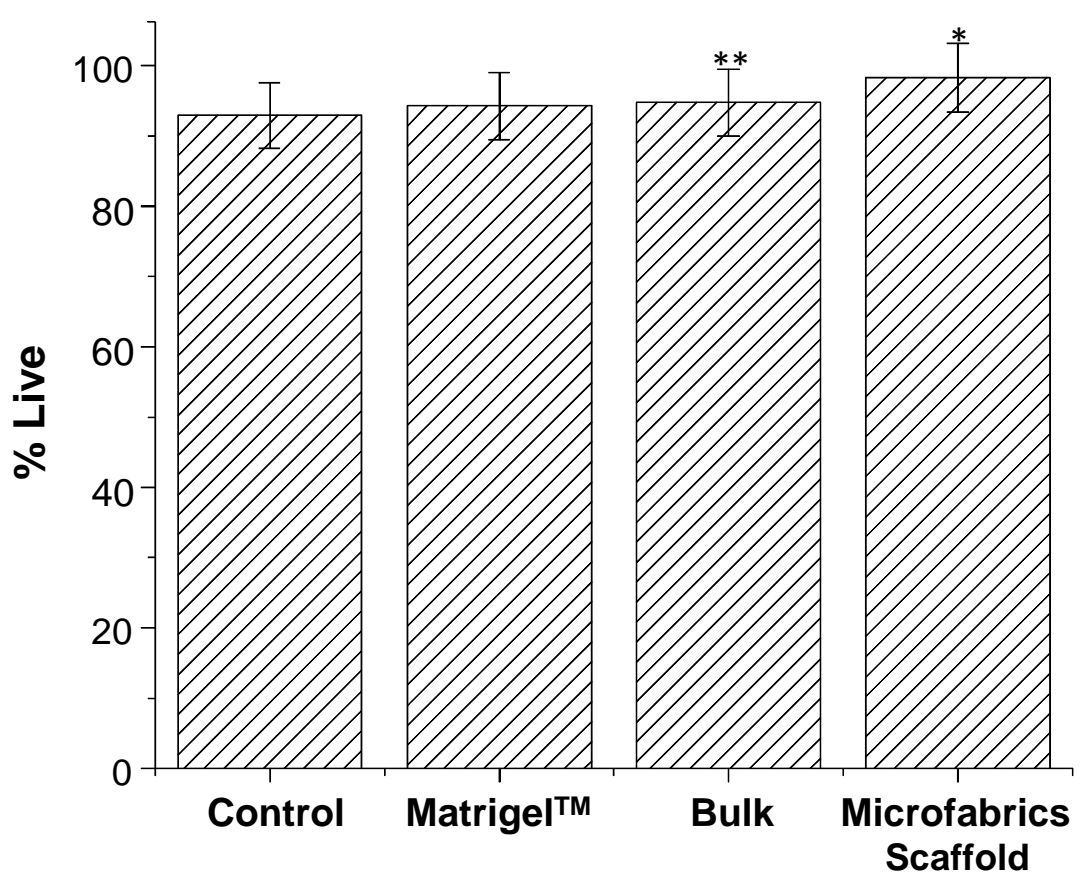

B)
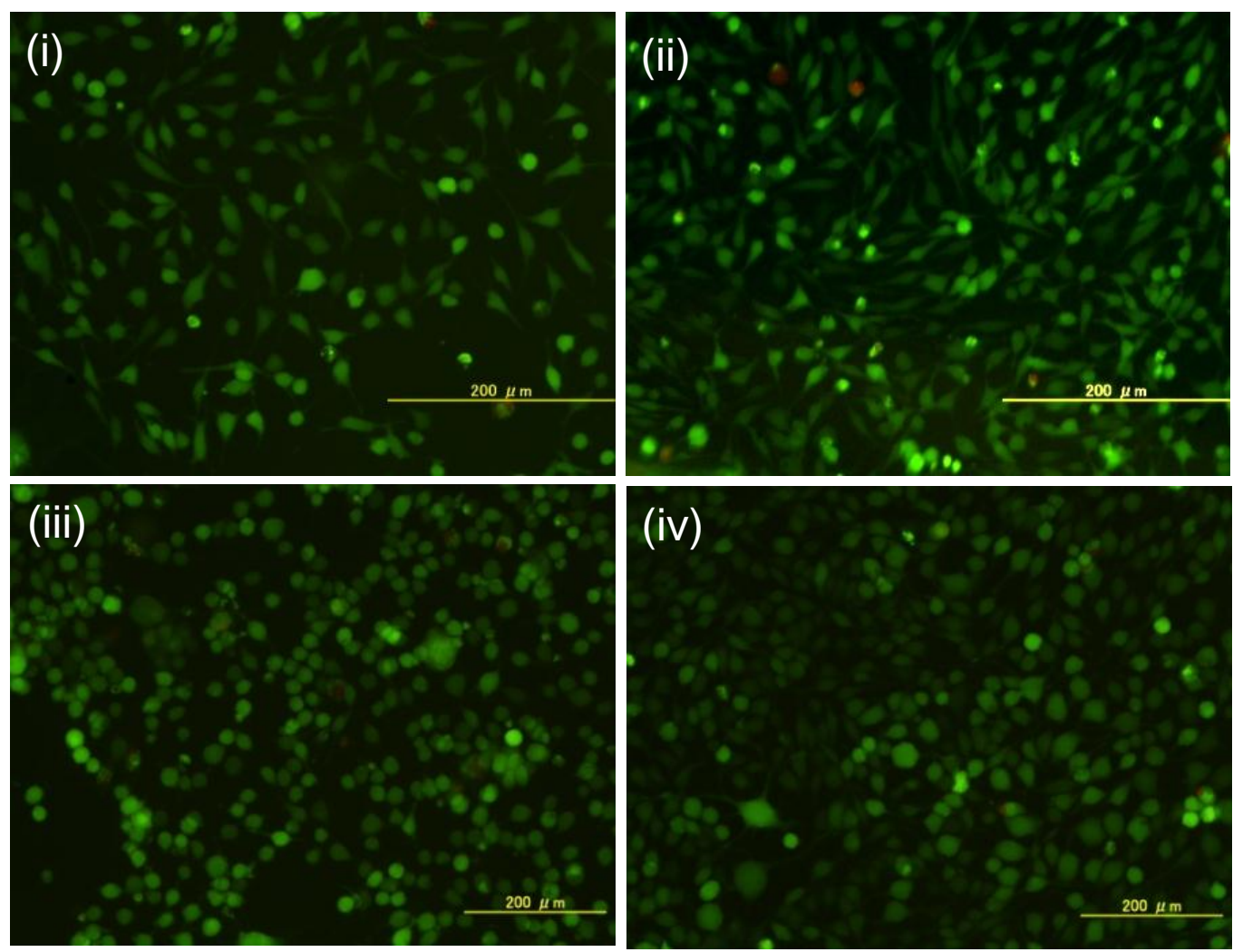

(iv)

Fig. 4. 

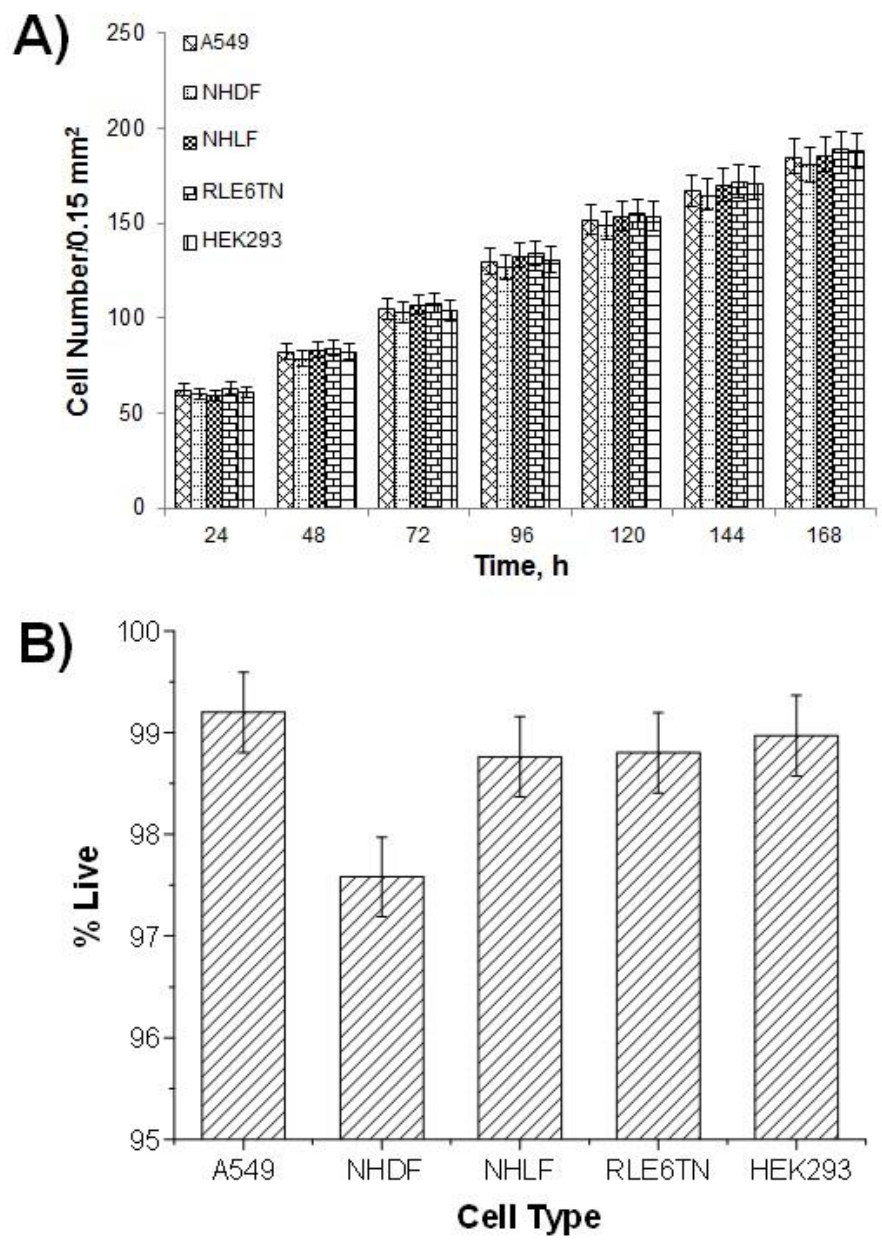

Fig. 5. 